\title{
La lucha antiimperialista de Las Casas
}

\author{
Rodolfo Cardenal \\ Centro de Reflexión Teológica, \\ San Salvador, El Salvador.
}

El imperialismo español justificó sus actos en América alegando una misión cristiana; la conquista y la colonia eran consideradas como una empresa evangelizadora; la encomienda y el régimen de pueblos eran instituciones destinadas a poner las bases de una supuesta sociedad cristiana. De esta manera, el imperialismo español encontró razones religiosas para justificarse, lo cual no es nada nuevo, porque todos los imperialismos, al final, encuentran razones de este tipo para justificarse a sí mismos. Lo verdaderamente novedoso es que desde la misma experiencia cristiana se encontraron razones suficientemente sólidas para cuestionar el imperialismo español del siglo dieciséis. A ninguno de los imperalismos de entonces le sucedió lo que al español, pues ninguno fue impugnado desde dentro y desde la misma fe que todos supuestamente compartian.

El cuestionamiento severo y la condena radical del imperialismo español se encuentran en el centro de la llamada controversia de Indias. La existencia mis ma de la controversia, tanto en la lejana corte peninsular como en las colonias españolas, muestra que, pese a todo, había mala conciencia. Fray Bartolomé de Las Casas fue uno de los protagonistas más importantes de esta controversia, que aquí nos interesa no por curiosidad academicista, sino por la actualidad que tiene su pensamiento y su acción frente a todos los imperialismos. La lucha antiimperialista de Las Casas pertenece de lleno a nuestra tradición latinoamericana. Este es un intento por recuperar sus principios teóricos y prácticos más importantes.

\section{La justicia: el gran tema lascasiano}

El primer aporte transcendental de Bartolomé de Las Casas en la controversia de Indias y para la tradición antiimperialista latinoamericana fue vincular la salvación a la justicia, es decir, para él no se podía predicar el evangelio si no había justicia. Esta relación muestra la profundidad cristiana, y teológica, de este 
fraile dominico, para quien no podía predicarse una buena noticia (el evangelio) en medio de una mala realidad, caracterizada por la violencia y la injusticia.

La codicia y la ambición de los conquistadores y de los primeros pobladores condenó al fracaso todo intento de evangelización, "porque es imposible que alguno se salve si no observa la justicia", sentenció Las Casas. Desde los albores del descubrimiento, el oro obsesionó a los españoles hasta convertirse en su dios. Colón lo expresó muy bien en una carta a los reyes, "el oro es el más precioso de todos los bienes, el oro constituye un tesoro, aquel que lo posee tiene todo lo que necesita en este mundo, así como los medios para salvar las almas del purgatorio y enviarlas al gozo del paraíso", puesto que puede pagar a quien rece por ellas. Estas líneas de Colón sintetizan con exactitud la mentalidad de los conquistadores y de los colonizadores españoles.

El deseo de enriquecimiento rápido los llevó a poner el oro por encima de los hombres, trastocando el orden natural y divino que, según Las Casas, establecía "que los hombres fuesen fin de todas las cosas, y no las cosas inferiores fuesen fin de los hombres". Al colocar el oro por encima de los hombres, sacrificaron éstos para conseguir aquél. La consecuencia más grave de esta trastocación fue la violencia y la injusticia. Las muertes y los robos cometidos no se debían, en primer lugar, al odio personal de los españoles hacia los indígenas, aun reconociendo la existencia de un racismo muy fuerte, pues "no pretendían directamente matarlos sino servirse de ellos como de animales, posponiendo la salud corporal y espiritual de los indios a sus intereses, codicias y ganancias, a lo cual seguírseles la muerte no era indubitable, sino necesario" (1542).

De esta manera, los españoles pusieron el oro como último de la conquista y de la colonia, y también como ultimidad de sus vidas personales. Hicieron del oro su ídolo y al consagrarle sus vidas se convirtieron en idólatras, generando así una paradoja insorportable, que Las Casas se encargó echarles en cara, puesto que aquéllos consideraban que la idolatría era lo propio de los nativos y no de ellos, que se consideraban cristianos fuera de toda duda. En cuanto idólatras, los españoles pusieron en juego su propia salvación y Las Casas no dudó en mandarlos al fuego eterno del infierno.

Pero no solamente se perdían ellos, sino también los nativos, porque los efectos de su idolatría - la devastación, la muerte y la destrucción- hacían imposible la vida humana e impedían la conversión de la población a la nueva fe, supuesto objeto fundamental de la empresa de conquista. Así, pues, la salvación de ambos estaba intrínsecamente relacionada. Este planteamiento de la salvación de los infieles no es teórico, sino que parte de la experiencia histórica de Las Casas.

Al vincular de esta manera salvación y justicia, Las Casas denunció el uso ideológico que se estaba haciendo de la necesidad de evangelizar las nuevas tierras, denunció la idolatría asesina y devastadora de los conquistadores y de 
los colonizadores, y recordó radical y vehementemente que la vida humana era prioritaria, incluso sobre la pretendida evangelización, porque si la muerte y la destrucción de la población eran condición para que fuera cristiana, mejor era que no lo fueran nunca. "No puede causarse ningún detrimento mayor que el de privar a algunos de la vida", repitió incansablemente Las Casas.

Para Las Casas, la denuncia de la injusticia era una exigencia aún más urgente porque se la estaba justificando presentándola como un medio para evangelizar. Sus textos más inequívocos e incisivos son aquellos donde denuncia, desenmascarando esa justificación. Esta postura lo llevó a enfrentarse con los encomenderos y los funcionarios reales en la colonia, pero también lo llevó a cuestionar a los reyes mismos, cosa literalmente inaudita en aquella época. Esta lucha por la justicia no tuvo lugar sólo en las cartas al rey y a su consejo ni sólo en las gestiones políticas cortesanas, sino que también la llevó al púlpito, donde en 1514 y ante el gobernador Velázquez, repitió el escándalo de los dominicos de La Española en 1511, quedando "todos admirados y aun espantados de lo que les dijo, y algunos compungidos, y otros como si lo soñaran, oyendo cosas tan nuevas como eran decir que sin pecado no podían tener los indios en su servicio".

Muchos de sus oyentes, como tres años antes los de fray Antonio de Montesinos en La Española, encontraron que "la novedad no era otra sino afirmar que matar estas gentes era más pecado que matar chinches". Del púlpito, la lucha pasó al terreno sacramental, al prohibir en su diócesis de Chiapas absolver a aquellos que tuvieran indígenas encomendados. En sus reglas para los confesores estableció que, antes de proceder a confesar a un conquistador agonizante, éste, "declare, y asiente el escribano, que no trajo hacienda alguna de Castilla, sino que todo lo que tiene es habido de indios o con indios...", es decir, todo lo que posee es robado. En consecuencia, no tiene derecho a heredarlo, aunque tenga cien hijos legítimos, "como no tenga cosa suya, no tiene qué dejar a sus hijos, ni qué heredar sus herederos". Una vez reconocidos estos hechos y liberados los nativos de toda servidumbre, el confesor podía absolver al penitente. En aquella sociedad española del siglo dieciséis profundamente creyente, negar la absolución, sobre todo a un moribundo, era condenarlo eternamente. Esta fue una de las causas por la que los diocesanos españoles de Las Casas, desesperados con su obispo, lo persiguieron hasta obligarlo a huir de su diócesis de Chiapas.

La raíz de la lucha por la justicia de Las Casas se encuentra en su fe cristiana. En efecto, desde la radicalidad de la creación, afirma que todos los hombres somos iguales, en cuanto que todos somos hijos y criaturas de un mismo Dios. A partir de la igualdad humana y de la dignidad de la persona, principios consagrados siglos más tarde por el derecho internacional humanitario, Las Casas afirma tajantemente que los hombres, por infieles que sean y por cualesquiera 
pecados que tengan, todos son sujetos de derechos. Es la afirmación absoluta de la dignidad humana como fuente de respeto y de libertad.

Justicia y salvación no sólo cran inseparables, sino que practicar la justicia en las Indias, es decir, denunciar aquellas prácticas que la negaban y promover la convivencia y la dignidad humana, en sentido amplio, era una forma de predicar la fe, que Las Casas y otros muchos obispos de entonces estimaban mucho. Sorprende que hombres como éstos, obsesionados por la evangelización, considerasen la práctica de la justicia como una forma de predicar muy importante. No identificaron fe y justicia, pero tampoco fueron reduccionistas. Comprendieron, conforme a la mejor tradición cristiana, que si no hay condiciones humanas dignas no se puede exigir ni fe ni moral.

Practicar la justicia, en cuanto acto de amor, es evangelizar. La predicación es una acogida, por lo tanto está reñida con la imposición y el autoritarismo. Este principio que puede parecernos muy obvio no lo era entonces, cuando, precisamente, se practicaba lo contrario y se creía tener derecho a ello. El fundamento de este principio que Las Casas compartió con la primera generación de obispos latinoamericanos del siglo dieciséis es, de nuevo, la dignidad de la persona humana.

Las Casas quiso demostrar en la práctica que sus argumentos eran verdaderos. Su visión era la de un nuevo mundo a donde emigraran campesinos españoles, a quienes se les daría una oportunidad para superarse al entregarles un pedazo de tierra para que vivieran y trabajaran al lado de los nativos. Su fe y sus técnicas serían absorbidas por éstos. Sobre estos presupuestos, Las Casas pensaba en una comunidad cristiana ideal, haciendo innecesaria la encomienda y la guerra. Así, pues, Las Casas promovió una emigración planificada con vistas a construir una comunidad sana y próspera de campesinos libres, no de soldados, nobles venidos a menos, aventureros y convictos, quienes hasta entonces integraban las bases de la nueva sociedad colonial. Este primer plan fracasó a principios de 1519.

Las Casas siguó luchando. La pregunta que quería responder no era estúpida. Todos los capítulos de su Historia de las Indias están llenos del apasionado relato de sus batallas, desde abril de 1519 , cuando fracasó su primer plan para reclutar campesinos españoles, hasta mayo de 1520 , cuando le concedieron un territorio en el continente. La autorización para establecerse en la franja costera de Paria a Santa Marta fue un gran triunfo. A cambio de la autorización, Las Casas garantizó pacificar y convertir a la población y organizarla en pueblos, de modo que, en dos años, el rey tendría diez mil vasallos pagando impuestos; asimismo, prometió explorar la tierra concedida e informar de sus posibilidades económicas. Todo ello sin gasto alguno para la corona. Parte de la autorización era que ninguno, por ningún pretexto, capturara a nadie, ni tomara propiedad indígena ni los tratara mal. 
La ambición dio al traste con esta nueva experiencia de evangelización pacífica en julio de 1521. En la medida en que Las Casas no tuvo control total del territorio, otros españoles, con intereses diferentes, crearon una situación tan tensa que fue imposible mantener relaciones pacíficas con los habitantes de aquel territorio. Pero Las Casas no abandonó su idea de que los naturales podían abrazar la nueva fe con medios pacíficos.

En 1537, Las Casas vuelve a intentar demostrar en la práctica la verdad de su idea, esta vez en las llamadas Verapaces, antes "Tierra de la guerra". Las ideas fundamentales de esta nueva experiencia están expuestas en $E l$ único modo de atraer a todos los pueblos a la verdadera religión. Los primeros pobladores de Santiago de Guatemala se rieron de Las Casas y sus ideas. Si fracasaba, aunque saliera con vida, se habría desacreditado para siempre. Para él, aquello era más que un simple experimento, era demostrar la verdad de Dios. El territorio que escogió para su intento no había podido ser penetrado por los españoles. La población ya había rechazado tres expediciones armadas. Las Casas y los dominicos penetraron pacíficamente, demostrando así su verdad. Durante una década, el ayuntamiento de Santiago y los dominicos pelearon sobre la predicación pacífica. En el curso de la lucha, aquél acusó a Las Casas de fraile iletrado, apasionado, turbulento, loco y enemigo de la presencia hispánica. Pero Las Casas fue apoyado por la corona. En 1544, fue designado obispo de Chiapas, cuya diócesis comprendía las Verapaces. Tres años después, en 1547, el conflicto con los colonizadores alcanzó su cima y tuvo que abandonar la diócesis. En 1550, renunció a ella, a los sesenta y cinco años de edad.

El experimento de las Verapaces terminó de mala manera en 1556, cuando un levantamiento nativo, instigado por un sacerdote prehispánico, atacó a los misioneros. Los rebeldes fueron castigados militarmente por orden del rey. La misma historia, con el mismo resultado, fue contada por Vasco de Quiroga una década más tarde. En los siglos diecisiete y dieciocho, los jesuitas probaron conclusivamente que podía establecerse una comunidad nativa y mantenerla, en sus famosas reducciones, en América del Sur.

La perspectiva de Las Casas es novedosa y radical, porque su punto de vista es el del indígena, pobre y oprimido. El versículo 22, del capítulo 34 del Eclesiástico - "quien derrama la sangre ajena y quien no paga el justo salario, hermanos son" - le comenzó a abrir los ojos para ver la realidad de Las Antillas primero y del continente después. El pensamiento lascasiano tiene sus fundamentos en la realidad indígena. Las Casas habla desde la experiencia. Sus afirmaciones vienen desde la práctica, incluso su discurso sobre la fe está arraigado en su práctica evangelizadora en las Indias. Tuvo plena conciencia de esto y lo repitió de mil maneras a lo largo de su vida. En 1531, en carta al consejo real habla de hechos "no leídos en historias fingidas ni contados por lenguas parleras, sino vistos por nuestros propios ojos, presentes a ellos nuestras personas". 
Aquí reside toda la diferencia de quienes como él optaron por los conquistados y colonizados. Quienes optaron por el indígena, lo hicieron de cara a la opresión y a la violencia. Las Casas gustaba rebatir a sus contradictores echándoles en cara que si hubieran estado en las Indias hablarían de otro modo. Ante la realidad injusta no era posible la neutralidad, sino la opción por el indígena. Para Las Casas, la opción era inevitable por el agravio que los indígenas habían recibido de parte de "nosotros, los españoles". Los obispos de entonces, además de los títulos ordinarios propios del cargo jerárquico, tenían el título de "protectores de indios", pero no era un simple título. Los españoles se quejaron repetidamente que más parecían obispos de indios que de españoles; alguno incluso se sintió agraviado porque aquellos obispos no se conducían como era de esperar de un jerarca.

Hoy como hace quinientos años es necesario seguir insistiendo en que no se debe matar. La mayor parte de la población latinoamericana se empobrece cada vez más y muere lentamente de desempleo, de enfermedad y de hambre. También ha muerto y sigue muriendo víctima de la violencia terrorista estatal y no estatal, y por causa de conflictos armados. No es éste el lugar para insistir en estadísticas, porque el hecho desnudo está ahí y es reconocido incluso por los grandes organismos financieros internacionales cuando ponderan los éxitos macroeconómicos del ajuste estructural. La muerte lenta de la población latinoamericana y del tercer mundo obliga a condenar la pobreza generalizada y creciente. Esa pobreza está causando el mayor daño posible al quitar la vida. Ya no se diga cuando la muerte se debe a acciones violentas. Frente a esta realidad, es necesario seguir afirmando que todos los hombres tenemos derecho a una vida digna, así como también es necesario seguir denunciando a los ídolos y a los idólatras responsables de tanta miseria y de tanta muerte.

La paradoja con la que se encontró Las Casas, en la actualidad la encontramos en aquellos que se presentan como salvadores de la humanidad o como portadores de los valores occidentales. Al presentarse de esta forma se arrogan el derecho para intervenir en las otras naciones, violando la soberanía de los pueblos y fundando imperios. En realidad, no salvan a ningún pueblo, sino que los destruyen y devastan; ni siquiera ellos mismos se salvan, porque en estas aventuras imperialistas acaban deshumanizándolos. Los resultados obtenidos son contrarios a los presupuestos proclamados abiertamente. En realidad, no puede ser de otra manera, puesto que no buscan ni el bienestar ni la felicidad de las otras naciones, sino la suya propia, por encima de cualquier otra y a pesar de las demás. La actualidad de esta paradoja hace relevante el antiimperialismo de Las Casas.

\section{El derecho de soberanía de todos los pueblos}

Las Casas llevó a cabo un gigantesco esfuerzo en La apologética historia 
sumaria para demostrar la igualdad natural y divina de los habitantes del nuevo mundo. La discusión teórica era vital, porque la conquista y la colonia estaban siendo justificadas alegando que la población del nuevo mundo era inferior. El esfuerzo teórico de Las Casas en La apologética es el más completo y el mejor de cuantos hubo en el siglo dieciséis frente a la crisis provocada por "la invención" de América y de los indios.

Ante la calumnia y la infamia hecha al indigena, al atribuirle falta de capacidad racional para gobernarse a sí mismo con "humana policía y ordenadas repúblicas", Las Casas emprende la tarea de dar a conocer la verdad histórica sobre las civilizaciones prehispánicas. El argumento más fuerte de Las Casas es el histórico. En efecto, la realidad histórica mostraba que los habitantes del nuevo mundo, cualesquiera que fueran las apariencias en contrario, gozaban de plena capacidad racional. Pese a la fuerza de la realidad histórica, Las Casas también argumenta desde la naturaleza, según los esquemas filosóficos predominantes entonces.

Su tesis es que en la población de las Indias concurren las causas naturales necesarias para la racionalidad. La esencia humana (la racionalidad) se realiza en ella plenamente, por lo tanto, desde el punto de vista natural, los indígenas son plenamente humanos. Esta afirmación contradice a quienes sostenían que la esencia humana no se realizaba en ellos de modo pleno, por lo tanto, no podían ser completamente humanos. El mejor representante de esta posición fue Ginés de Sepúlveda, para quien era lícito que el rey de España hiciera la guerra para someter a los indígenas a su imperio, de modo que luego fuera más fácil instruirlos en la fe. Según Sepúlveda, los indígenas eran naturalmente inferiores y siervos de los europeos, quienes eran sus amos naturales. Por consiguiente, el sometimiento era conforme a la naturaleza humana y las guerras para lograrlo estaban totalmente justificadas.

En el texto conocido como el "Requerimiento" se sintetiza el planteamiento de quienes como Ginés de Sepúlveda defendían la guerra. El "Requerimiento" es un texto curioso porque, además de justificar la guerra y la esclavización de la población nativa, intenta una justificación teológica del uso de la fuerza para anunciar el evangelio. Después de anunciar la donación papal de las Indias a los reyes de Castilla para que las evangelizaran, se requiere a la población acatar dicha donación, es decir, "a la Iglesia por Señora y superiora del Universo Mundo, y al Sumo Pontífice llamado Papa en su nombre, y al Emperador e Reina doña Juana nuestros señores en su lugar, como a superiores y Señores y Reyes de estas islas y tierra firme en virtud de la dicha donación". Si así lo hacían "os recibiremos con todo amor y caridad", pero en caso contrario, "con la ayuda de Dios nosotros entraremos poderosamente contra vosotros, y os haremos guerra por todas las partes y maneras que pudiéremos, y os sujetaremos al yugo y obediencia de la Iglesia, y al de sus Magestades, y tomaremos vuestras 
personas, e a vuestras mujeres e hijos, e los haremos esclavos, e como tales los venderemos, y dispondremos de ellos como sus Magestades mandaren, e os tomaremos vuestros bienes, e os haremos todos los daños e males que pudieremos, como a vasallos que no obedecen ni quieren recibir a su Señor y se le resisten y contradicen...". La clave del texto está al final, porque en él se justifica la esclavización de la población y el despojo de sus reinos, señorios y bienes. El "Requirimiento" no fue elaborado para que la población lo entendiese y aceptase, evitando así la guerra y la destrucción, sino precisamente contando con que no lo aceptaría, con lo cual se justificaba legalmente la esclavitud y el despojo.

Las Casas rebate estos argumentos desde la perspectiva de la naturaleza, pero no se queda ahí, pues el modo de vida de la población revela que era, efectivamente, humana. Las Casas discute y polemiza dentro del horizonte de las tesis clásicas. No podía ser de otra manera, puesto que todos los que participaron en la controversia de Indias tenían la misma mentalidad clásica. Lo sorprendente es que Las Casas haya encontrado, dentro de ese esquema clásico, una salida novedosa y sólida.

La racionalidad es la esencia que define al hombre $y$, en tanto esencia, es inalterable y siempre idéntica a sí misma. Por consiguiente, se da en todos los hombres y no puede sino darse plenamente en cada uno de ellos. Este darse inalterable de la esencia es lo que permite hablar de especie y de una igualdad ontológica. Las diferencias históricas y culturales no pueden esgrimirse como negación de la plena realización de la esencia racional. Más bien, son accidentales. La historia no afecta en nada a la esencia, siempre igual a sí misma; ni puede afectarla dentro de este esquema filosófico, porque entonces dejaría de ser esencia. En el fondo, la historia no tiene mucha importancia. Aunque esta concepción de la historia nos pueda parecer extraña en la actualidad, no hay que perder de vista que aquí lo trascendental es afirmar la igualdad ontológica, porque, sin esa igualdad, habría grados en la realización de la esencia y en la humanidad, que justificarian fácilmente la dominación de unos sobre otros.

Sin embargo, la dimensión histórica de la realidad es importante para Las Casas. La segunda parte de su argumentación se funda en la experiencia histórica de las sociedades y civilizaciones prehispánicas, cuya complejidad y sofisticación confirma y ratifica la plena realización de la esencia racional en sus miembros. Más aún, los argumentos más fuertes contra la conquista y la colonia son los históricos. El poder de la realidad es tal, que Las Casas lo introduce de modo natural en la discusión teórica. En efecto, la historia descalifica las tesis de Sepúlveda y las responsabiliza por ser causa "de la perdición de tan infinitas gentes y despoblación de más de mil leguas de tierra, que han muerto y despoblado con nuevas y diversas maneras de crueldad e inhumanidad de los españoles en las Indias, conviene a saber: las que llaman conquistas y las encomien- 
das...". La mejor manera de refutar está en las consecuencias prácticas y no en los argumentos teóricos. Las Casas reprochó muchas veces a Sepúlveda su intelectualismo y su falta de conocimiento directo.

Ahora bien, la argumentación lascasiana tenía una dimensión universal, que conviene rescatar. La tesis de la incapacidad racional propugnaba un nacionalismo exagerado y condenable porque, al admitir la existencia de grados en la realización de la esencia humana, introducía también la tesis aristotélica de que lo superior y más excelente debe dominar sobre lo inferior e imperfecto. Estas afirmaciones niegan que los pueblos tengan derecho soberano a perseguir el destino común de la humanidad por cuenta propia. Como algunos pueblos no tenían capacidad racional suficiente para convivir civilizadamente, debían ser tutelados por otros que sí la tenían en plenitud. Lo justo no consiste en conceder los mismos derechos a todos los pueblos, pues no todos son iguales. No se pueden otorgar iguales derechos a cosas desiguales.

Además, los pueblos civilizados harían un inmenso bien a los no civilizados, llevándolos de la mano al destino común de la humanidad. En consecuencia, el mayor servicio que podía recibir el pueblo bárbaro era ser dotado de esa humanidad, de la cual carecía, por aquel otro que era ejemplar. La nación civilizada por excelencia no sólo tiene derecho, sino la obligación moral de intervenir en la vida de los pueblos bárbaros, arrogándose su soberanía para civilizarlos $\mathrm{y}$, si fuera necesario, debe imponerles por la fuerza sus ideas y sus instituciones y así llevarlos a la verdadera religión e implantarles las buenas costumbres.

En el siglo dieciséis, la consecuencia de este discurso lógico era inevitable. España era la nación escogida para llevar a cabo esta misión, puesto que no existía pueblo más civilizado que fuera más prudente, ingenioso, fuerte, humano, justo, religioso y, en general, relevante en todas las virtudes políticas y cristianas. La historia española se ofrecía, y debía imponerse por la fuerza, a los demás pueblos como la historia paradigmática.

Si filosóficamente Las Casas afirma la igualdad ontológica, teológicamente, todos los pueblos tienen a Dios en su origen y asimismo lo encontrarán al final de su historia. Dios se encuentra en el origen creatural y al final, a donde debe llegar la creación entera. En consecuencia, el destino del hombre y de los pueblos está más allá de las circunstancias contingentes. Las historias particulares son contingentes - de hecho, para este tipo de pensamiento, la historia es lo contingente por excelencia-, y en cuanto tales, no afectan el destino divino de la humanidad. Para Las Casas es indudable que cada pueblo llegará al destino común de la humanidad, Dios mismo. El movimiento de la historia obedece a sus designios inescrutables. Por consiguiente, las diferencias culturales, étnicas o religiosas no son más que accidentes a través de los cuales los pueblos no pueden sino alcanzar su destino sobrenatural. 
Pese a ser contingente, la historia no es despreciada por Las Casas, puesto que reconoce que cada pueblo tiene derecho a darle su propio sentido y dirección. Para él es inaceptable que un pueblo supuestamente mejor se apodere del destino de otro presuntamente inferior, porque ello significa anular la propia historia, vaciándola de sentido y dejándola sin dirección. Entrar en la comunidad de las naciones civilizadas no puede implicar la renuncia a la propia historia para reemplazarla por la de aquéllas. Ninguna historia es ejemplar ni paradigmática, tampoco ninguna posee exclusivamente el derecho natural y divino. Todas las naciones tienen derecho a la suya propia y no son intercambiables. La importancia del argumento teológico reside en quitar fundamento a quienes quieren reemplazar las historias particulares por una única historia paradigmática extraña. Las Casas argumenta recurriendo a lo último, al fundamento divino de la creación y del destino de los pueblos. Para poder afirmar sólidamente la soberanía de los pueblos debe negar radicalmente la existencia de una sola historia ejemplar, en cuyo nombre se quieren anular aquéllas otras. En este sentido estricto, lo único absoluto es Dios y su designio sobre la creación y la historia.

Históricamente, cada pueblo debe buscar por sí mismo su propio bienestar colectivo y, en definitiva, su salvación. Para Las Casas es sencillamente imposible que toda una nación o raza, por estúpida e idiota que sea, carezca en absoluto de la capacidad para realizarse humanamente y acoger la fe. Por otro lado, este principio no se aplica a la población del nuevo mundo porque, tal como Las Casas observó, ésta era inteligente; más aún, la mayoría de ella poseía una inteligencia excepcional.

Por lo tanto, y aquí viene la gran conclusión, "todos los infieles, de cualquier secta o religión que fueren y por cualesquier pecados que tengan, cuanto al derecho natural y divino y el llamado derecho de gente, justamente tienen y poseen señorío sobre sus cosas..., y también con la misma justicia poseen sus principados, reinos, estados, dignidades, jurisdicciones y señoríos" (declaración de la reunión de obispos de 1546, convocada por Tello Sandoval y a la cual asistieron los obispos Marroquín de Guatemala, López de Zárate de Oaxaca, Vasco de Quiroga de Michoacán y Las Casas de Chiapas). Entonces, "todas las guerras que llamaron de conquistas fueron y son injustísimas y de propios tiranos" y "todos los reinos y señoríos de las Indias tenemos usurpados". Ni siquiera las guerras hechas con el pretexto de favorecer la evangelización estaban justificadas, "la guerra que se hace a los infieles... por respeto de que mediante la guerra sean sujetos al imperio de los cristianos y de esta suerte se dispongan para recibir la religión cristiana o se quiten los impedimentos que para ello pueda haber, es temeraria, injusta, perversa y tirana" (declaración de los obispos de 1546).

Las Casas no negó la obligación de predicar el evangelio a toda criatura, 
pero proclamó que todos los pueblos han sido llamados por Dios para recibir la fe como gracia. La providencia ha establecido para todos los pueblos y para todos los tiempos un solo, mismo y único modo para enseñar a los hombres la verdadera religión: la persuasión del entendimiento por medio de razones y por la invitación suave de la voluntad. Las Casas prueba su tesis en treinta y seis largo capítulos, que se remontan al Antiguo Testamento. En ellos establece que la tradición cristiana es contraria a la imposición y, por supuesto, a la guerra. El recurso a la guerra para predicar era una invención humana contraria a la ley divina.

Las Casas sólo concede una única posibilidad de intervención legítima, la firma de un tratado entre el rey de Castilla y los reyes del nuevo mundo, pero antes, éstos deben haberse convertido a la fe, junto con sus súbditos, libre y voluntariamente, "en las Indias el rey de Castilla ha de ser reconocido como supremo príncipe y emperador sólo después de la conversión a la fe y la entrada en el cristianismo de los reyes y señores naturales de aquellos reinos así como de sus súbditos, habiéndose sujetado al yugo de Cristo a sí mismos y a sus reinos por propia voluntad y no por violencia ni fuerza previo tratado y convenio entre el rey de Castilla y ellos". Lo primero es la conversión libre y voluntaria, y no el reconocimiento de un soberano extraño. Pero resulta que la conversión a la fe implica también reconocer la libertad política y el derecho a la soberanía, no al revés, que es lo que pretendían conquistadores, gobernadores y reyes.

En el tratado, si es que se llegaba a él, "el rey de Castilla debe prometer bajo juramento que su superioridad les será buena y útil, además de la permanencia y conservación de su libertad, señorío y dignidades, derechos y leyes razonables anteriores. Por su parte, pueblos y reyes deben prometer jurar a los reyes de Castilla el reconocer su superioridad de príncipe supremo, así como la obediencia a sus leyes y mandatos". Así, pues, primero debía quedar asegurada, bajo juramento, la bondad y la utilidad de reconocer la soberanía de los reyes de Castilla, así como también debían quedar debidamente garantizadas la libertad de la población y su soberanía. En la práctica, era imposible garantizar ambas cosas al mismo tiempo, por lo tanto, lo que en teoría era posible, en la práctica no lo era.

"Y si los reyes de Indias quisieran traspasar a los de Castilla su derecho sobre las minas de oro y plata, perlas, piedras y salinas, que les pertenecen como propias y por derecho real de los reyes establecidos, prestarán entonces a nuestros reyes un señalado servicio, y estas concesiones no deben entrañar servicios gratuitos ni de ellos ni de sus súbditos, sin su voluntad". En último lugar estaría la entrega, siempre voluntaria, de sus recursos naturales. Sin embargo, Las Casas subraya que la propiedad de los mismos pertenece a los pueblos de Indias y, en cuanto tal, sólo ellos podrían entregar dichos recursos. Finalmente, si se 
llegara a hacer el traspaso, ninguno estaría obligado a trabajar para los españoles.

En consecuencia, Las Casas rechaza la tesis que afirma la necesidad de la guerra como un paso previo para evangelizar y condena a quienes emprenden tales guerras, porque estarían privados del amor de Dios, en realidad, odian a Dios. Asimismo, rechaza la tesis modificada que sostiene que la guerra es necesaria para suprimir los obstáculos que impiden a los misioneros predicar la fe, pero dejando en libertad a los naturales para aceptarla o rechazarla. La modificación también es absurda y disparatada, porque lo único que se consigue es un resentimiento perdurable y una conversión fingida por miedo a sufrir males peores. Quienes mantienen y practican estas tesis son, para Las Casas, los precursores del anticristo y los secuaces de Mahoma por su método de convertir a sangre y fuego. El rey "no puede justificar las guerras y robos hechos a estas gentes... más que justificar las guerras que hacen los turcos al pueblo cristiano".

La guerra contra los infieles de tercera categoría (aquellos que nunca habían tenido conocimiento de la fe ni de la Iglesia y que nunca habían ofendido a ninguna de las dos) es "temeraria, injusta, inicua y tiránica", contraria a la ley natural, divina y humana. La guerra es el método más miserable y criminal, un método usado por ladrones y por los más impíos. Por consiguiente, quienes las emprenden o contribuyen a ellas de cualquier modo, pecan mortalmente. Asimismo, todos los que las han causado están obligados, como requisito previo para salvarse, a restituir a los infieles todo lo que les ha sido arrebatado y a reparar todos los daños ocasionados por causa de tales guerras, "si no lo restituyen los que lo han robado y hoy roban... y los que de ello participan no podrán salvarse".

Las Casas no tenía duda alguna sobre la extensión del daño que debía ser satisfecho, aunque bien sabía que ni la angustia ni el sufrimiento ocasionados podían ser reparados. En su último memorial al Consejo de Indias, de 1566, Las Casas insiste, "todo cuanto oro y plata, perlas y otras riquezas que han venido a España es todo robado".

\section{Conclusión}

El gran enemigo de Las Casas fue la encomienda y los comienzos de la vida colonial, que esclavizaban y mataban, y la razón última de su lucha fue el anuncio del evangelio de Jesucristo y la salvación plena de los fieles y de los infieles. Rechazó la conquista, cuestionó hasta la desautorización la soberanía de los reyes españoles sobre los nuevos territorios y sus poblaciones y proclamó el derecho a la soberanía de todos los pueblos. Lo repitió en todos los tonos, hizo gestiones ante diferentes autoridades civiles y religiosas, propuso modos para combatir a los encomenderos, polemizó contra sus argumentaciones filosóficas y teológicas, ensayó experiencias de evangelización pacífica y escribió varios tra- 
tados proclamando la humanidad de los nativos.

Quinientos años más tarde, la afirmación de la soberanía de los pueblos, de cualquier pueblo, por diferente que sea, y el rechazo de la guerra como medio para civilizar, o predicar una fe, incluida la fe en la democracia y en la libertad, siguen teniendo gran actualidad y trascendencia. Estos principios son válidos ante cualquier imperialismo, pero ahora lo son más ante Estados Unidos que, precisamente, en nombre de la libertad y de la democracia, impone por el chantaje económico y por la fuerza su modelo socioeconómico, político y cultural. Es una nación que, al igual que España hace quinientos años, se considera como la más civilizada, la más justa y la más libre. Es la nación superior a todas las demás, que deben someterse a sus dictados, abandonando en sus manos sus destinos y su dirección política.

Y cuando los pueblos se resisten a adoptar esas imposiciones, cuando las naciones levantan con dignidad su soberanía, Estados Unidos se erige en la nación ejemplar y aduce el inexistente derecho a imponer por la fuerza, y si es necesario por la guerra abierta, su voluntad. La única razón que asiste a Estados Unidos es la razón de la fuerza militar, de hecho, la razón de todos los imperios. Hoy, al igual que ayer, estas imposiciones y estos autoritarismos sólo dejan devastación y muerte. Mucho más cuando se lanza a nuevas campañas para "extirpar idolatrías" contemporáneas -llámense éstas comunismo o narcotráfico. Ni la democracia, ni la libertad, ni la justicia se promueven ni se defienden con la guerra. Tampoco se justifica como un simple medio para remover los obstáculos que las hacen imposibles.

Los imperialismos, incluido el estadounidense, ni son salvadores ni portan otros valores que los del mismo imperialismo, la devastación y la muerte. Estos resultados niegan radicalmente lo que proclaman de modo oficial. Así, resulta que las propias idolatrías son más importantes que las que dicen perseguir. Todavía hoy sigue siendo un principio fundamental que el mal mayor es quitar la vida. Y como ningún imperialismo estả libre de la opresión y de la violencia, ninguno está justificado y todos ellos deben ser denunciados y desenmascarados.

Todos los imperialismos, pero más el actual, están obligados a restituir lo que han robado a los pueblos dominados y expoliados. Con Las Casas hay que repetir incansablemente hasta el final que "todo cuanto oro y plata, perlas y otras riquezas" que han ido al norte, "es todo robado". La inmensa riqueza y el escandaloso nivel de bienestar del primer mundo proceden, en buena medida, del tercero. Es fruto del despojo. Cuando vinieron por primera vez al tercer mundo no trajeron nada. Al igual que Las Casas, no podemos conformarnos con constatar el hecho en sí, sino que debemos exigir la restitución de lo robado. Este es el reclamo de los pueblos del tercer mundo desde hace quinientos años.

San Salvador, abril de 1992. 